\title{
O IMPOSSÍVEL E A POÉTICA DA EXTRAÇÃO EM TREE OF CODES: UM EXERCÍCIO EM CAMPO EXPANDIDO
}

\section{THE IMPOSSIBLE AND THE POETICS OF EXTRACTION IN TREE OF CODES: AN EXPANDED FIELD EXERCISE}

\author{
Camila Backes Dos Santos ${ }^{1}$, Simone Zanon Moschen ${ }^{2}$
}

\begin{abstract}
RESUMO: O objetivo deste trabalho é discutir a noção de poética da extração como um operar que decanta efeitos de criação do trabalho de subtração/perda. Para tanto, parte da articulação entre os estudos de Rosalind Krauss (1979), em que a autora deriva a proposição de campo expandido do delineamento de uma noção de escultura que se ergue a partir da composição de negativos, e o trabalho do escritor norte-americano Jonathan Safran Foer, que escreve o livro Tree of codes operando uma verdadeira exumação da obra de Bruno Schulz, A Rua dos Crocodilos. A articulação desses trabalhos permite delinear condições de localização de um impossível que resta indicado, sem ser apreendido, e que acaba por fazer incidir efeitos de expansão sobre campos, como os da literatura, da arte e os estudos da memória, bem como por ver surgir o que nos permitimos chamar de um livro-objeto-escultura-obra-de-arte.
\end{abstract}

$\boldsymbol{P A L A V R A S - C H A V E : ~ c a m p o ~ e x p a n d i d o ; ~ p o e ́ t i c a ~ d a ~ e x t r a c ̧ a ̃ o ; ~ e s c u l t u r a ; ~ l i t e r a t u r a . ~}$

ABSTRACT: The present study aims to discuss the poetics of extraction notion as an operation that decants effects of creation due to the work of subtraction/loss. Therefore, part of the interrelation between the studies of Rosalind Krauss (1979), in which the author elaborates from the expanded field proposition the delineation of a sculpture notion that rises from the composition of negatives, and the work of American writer Jonathan Safran Foer, who has written the book Tree of codes while performing a true exhumation of Bruno Schulz's The Street of Crocodiles. The articulation of these works makes it possible to outline conditions of location of an impossible that remains indicated, without being apprehended, and that ends up focusing on effects of expansion on fields such as literature, art and memory studies, as well as seeing the emergence of what we allow ourselves to call a book-object-sculpture-work-of-art.

KEYWORDS: expanded field; poetics of extraction; sculpture; literature.

\footnotetext{
${ }^{1}$ Pós-doutoranda PNPD CAPES do Programa de Pós-Graduação em Diversidade Cultural e Inclusão Social na Feevale.

2 Professora do Departamento de Psicanálise e Psicopatologia do Instituto de Psicologia da UFRGS e do Programa de Pós-Graduação em Psicanálise: Clínica e Cultura e do Programa de Pós-Graduação em Educação da UFRGS.
} 


\section{Introdução}

De uma narrativa surge outra narrativa, de uma história extrai-se e recorta-se outra história. Nessa passagem-travessia algo permanece na forma de uma ausência - uma ausência registrada nos buracos visíveis sobre a página ou imagem original. Assim como um artista que produz uma escultura retirando, magistralmente, parte do material que tem em mãos, Jonathan Safran Foer produziu um livro-escultura-objeto-obra-de-arte: uma espécie de ornitorrinco a fazer furo na taxonomia que permite classificar os livros. Diante de Tree of codes, podemos lê-lo como a um livro, manuseá-lo como a uma escultura, contemplá-lo como a uma obra de arte.

O trabalho a seguir toma o livro de Foer, Tree of codes, como uma produção emblemática do que Rosalind Krauss propôs, partindo de seus estudos sobre a escultura, como um campo expandido. A autora estabeleceu essa noção no texto "Sculpture in the Expanded Field", de 1979, publicado originalmente na revista October. Os processos de corte, escavação e exumação operados por Foer, no livro de Schulz, fez surgir um livro que podemos predicar de "impossível": um livro-escultura-objeto-obra-de-arte impossível de ser reproduzido em outras mídias que não a que lhe deu origem. Este livro-impossível foi o resultado do trabalho de leitura/corte/escrita operado sobre uma obra já escrita, The Street of Crocodiles(1934), de Bruno Schulz (1892-1942). Esse processo compõe o que propomos chamar de uma poética da extração (BACKES; MOSCHEN, 2020), fazer que situa na subtração a via régia para criação.

\section{Tree of codes}

Em 2009, Foer foi convidado pela editora inglesa Visual Arts a produzir, por livre escolha, algo atípico. ${ }^{3}$ Primeiramente, pensou em recortar um dicionário, uma lista telefônica

\footnotetext{
${ }^{3}$ Tree of Codes é um dos títulos mais celebrados da editora. Ganhou o prêmio D\&AD em Book Award e Book Design em 2011. A Visual Editions conta ainda com o livro de Adam Thirwell, Kapow!, "Um estruturado caos de histórias impossível de decifrar", aponta o The New York Times. A editora também se dedicou à produção de uma nova versão do livro do escritor francês Marc Saporta, Composição No 1, de 1962. Este foi o primeiro livro a ser colocado em uma caixa, com folhas soltas que podem ser lidas em qualquer sentido. Nota: Tree of codes também serviu de inspiração para o balé contemporâneo de
} 
ou um romance seu. Porém, decidiu tomar como plataforma de criação a tradução inglesa de A Rua dos Crocodilos, realizada em 1977 por Celina Wieniewska e publicada pela editora Penguin Classic. Sobre esse livro operou uma série de cortes que resultaram na extração de parte importante das palavras e/ou frases, mantendo uma série delas na ordem em que aparecem no original de Schulz.

Foer, nesse livro, trabalhou utilizando-se de uma técnica artística chamada die-cut, originalmente proposta por Brion Gysin e William Burroughs na década de 1960, que consiste em extrair parte do original para formar, com o que resta, uma nova história ou imagem. Tree of codes é uma combinação de frases genuinamente desconectadas de maneira harmônica e poética. A narrativa é uma mescla de poesia e ficção que conta, aos olhos da família, o declínio de um pai e seu encontro com a loucura. O livro-escultura-objeto-obra-de-arte pede ao leitor delicadeza no seu manuseio (Figura 1). Esse cuidado necessário no encontro com o texto nos indica a presença de certa fragilidade. Fragilidade do objeto que temos em mãos, fragilidade do pai, personagem principal da história, fragilidade do registro quando busca dar conta de algo que bordeja a catástrofe - duplicação do conteúdo em forma, tão recorrentemente presente em muitas das produções artísticas de nosso tempo.

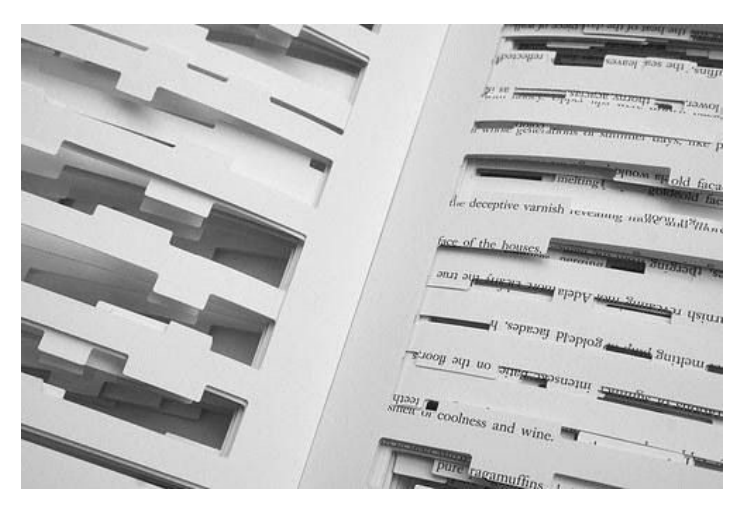

Figura 1 -Tree of codes

Fonte: site da editora Visual Editions.

O enredo testemunha o olhar de um menino que vai acompanhando e narrando o desfalecimento do pai. A extração através do recorte cria o vazio necessário a uma nova configuração, possibilitando, assim, a emergência de novos sentidos. Um texto em camadas que expõe as entranhas do que está em causa na escrita/leitura: ler é extrair para escrever,

Wayne McGregor, em 2015, no Festival Internacional de Manchester. O balé contou com a arte de Olafur Eliasson, apresentando-se pela Europa e pelos Estados Unidos. 
então, um sentido - às vezes novo. "Ele disse que perdeu seu caminho e mal sabia como voltar. Talvez a cidade tivesse deixado de existir? Talvez os espaços sugeridos pelo vento não existissem? Apenas uma invenção de solidão confusa e desconectada.” (FOER, 2010, p. 106-107). ${ }^{4}$

Nessa poética da extração, noventa por cento da obra de Schulz foi recortada, mantendo-se dela apenas dez por cento de sua estrutura para a nova composição narrativa. Conservando exatamente a mesma ordem das palavras do livro de Schulz, Foer faz aparecer uma nova história construída a partir de seus restos originais. O processo de exumação feito na obra do escritor polonês é visível ao leitor que, tendo o livro em mãos, manuseia as cento e vinte e sete páginas recortadas atravessando o perigo do rompimento... das folhas. Para Wurth (2011), no artigo "Old and new medialities in Foer's Tree of Codes", o livro instala-se nos limiares entre o verbal e o visual para fazer surgir um sentido escultural: "A escritura em si é esculpida com as palavras disponíveis para Foer, criando imagens não convencionais e originais" (POLTIER, 2016-2017, p.7, tradução nossa). ${ }^{5}$

\begin{abstract}
Neste processo poucas palavras restaram: uma adaptação cortada [die-cut] do livro de Schulz, se pensarmos em adaptação como apropriação (ver Sanders). Isso significa que Foer não foi fiel, este livro tem uma configuração diferente; em vez disso, ele distorce, desloca e descentra-o em uma nova configuração. (WURTH, 2011, p. 6, tradução nossa) ${ }^{6}$
\end{abstract}

A escultura de papel ou o livro-escultura não é uma simples adaptação da obra de Schulz, há um processo de inversão em jogo. As cento e trinta e quatro páginas que suportam a escultura também carregam o apagamento, o corte, a extração, o vazio, a ausência e o impossível posto em cena. Cortar o texto de um outro, cavar, extrair de lá palavras para fazê-las suas e criar um novo texto. A extração através do recorte cria o vazio necessário a uma nova configuração, possibilitando, assim, a emergência de novas formas. Um texto em camadas que permite colocar a céu aberto as operações envolvidas e um processo de leitura: cortar para ler/escrever (BACKES; MOSCHEN, 2020).

\footnotetext{
${ }^{4}$ No original: "He said he had lost the way and hardly knew how to get back. Perhaps the city had ceased to exist? Perhaps the city had ceased to exist? Perhaps the spaces suggested by the wind did not exist? Only an invention of loneliness confused and unconnected."

${ }^{5}$ No original: "The writing itself is also shaped by the words available to Foer, creating unconventional and original images."

${ }^{6}$ No original: "[...] a few words remaining: a die-cut adaptation of Schulz's book, if we think of adaptation as appropriation (see Sanders). This means that Foer does not faithfully re-render this book in a different setting; rather, he distorts, displaces and decenters it into a different configuration."
} 
Para a feitura do "corpo" do livro foram necessárias algumas etapas. Tomando em mãos o manuscrito-obra-de-arte de Jonathan Safran Foer, um grupo de pessoas se colocou a reproduzi-lo, cortando manualmente cada página com um estilete. Esta reprodução manual era necessária para criar as lâminas (facas) que dariam origem a cada página. Uma lâmina individual para cada página, diferente de um "livro comum”, que utiliza para todas as páginas a mesma lâmina (faca). Assistir à sua criação é como assistir a uma cena artística. Há algo também em seu processo de criação que faz resistência às produções em massa e em larga escala. Sua feitura insere a artesania singular em um processo fabril. Para cada página, uma lâmina, e não para todas as páginas a mesma lâmina. Com esse material manufaturado pronto, foi possível "desenhar" um protótipo que seria enviado para a gráfica para que se construísse a lâmina de cada página.

Em Tree of codes é a mão (e não apenas o olho) o motor que faz funcionar a engrenagem da leitura. Tateamos para ler. É como se essa experiência nos conduzisse a um retorno no tempo e na história da leitura. A obra de Foer convoca a entrada de um terceiro na relação olhar e livro; o terceiro elemento que entra na cena e que produz o sentido é o tato, a mão. Apenas o livro e o olhar não permitirão a experiência de leitura necessária para esse encontro. A experiência se produz também pelo toque, em um movimento quase sensual de contato. Ler em movimento: não é o leitor que se movimento para poder ler, mas sim a página que deve estar em movimento para que a leitura aconteça. Barthes (2012) nos lembra que o processo de leitura acontece quando levantamos os olhos da página. Em Tree of codes, a leitura acontece não apenas quando levantamos cada página, mas quando nossos dedos entram nos buracos das páginas e ameaçam rasgá-las, nessas idas e vindas, entre brutalidade e fragilidade. Às vezes, como Foer nos provoca, um único recurso não é suficiente para que a leitura aconteça, e, por isso, precisamos que o leitor observe o movimento para ler. "He would fall ( ) eard ( ) whispers, of ed ge transformed h ( ) storm of sobs” (FOER, 2010, p. 30). Lendo "apenas" a página "certa", lemos assobios. Se deixarmos as palavras das outras camadas comporem a leitura, leremos: "ele cairia, (ouviu) assobios, transformou-se tempestade de soluços”. O livro apresenta-se ao leitor em camadas que revelam, ao mesmo tempo, as palavras da página superficial e algumas das folhas subsequentes que saltam das camadas inferiores podendo compor um sem número de novas frases e combinações com a página de cima, a depender do gesto de leitura. Torna-se impossível estabilizar uma única sequência de palavras a compor a frase e a página. Hayles (2013, p. 230) chamou de hole 
words, ou "palavras-buraco", as palavras que saltam das páginas de baixo para a página de cima

A cada virada de página temos uma nova forma ou uma nova escultura de palavras. Diferente de quando viramos a página de um livro "comum" para dar continuidade ao enredo, neste, parece que viramos a página também para fugir da ausência de sentidos, do fosco, nebuloso. O movimento de virar a página se faz necessário para que a história siga e para que não nos percamos na página parada, sobreposta, sem sentido, que faz convite à vertigem. $\mathrm{O}$ sentido se faz com o movimento de subida, de desprendimento do local anterior, parado e obtuso, com a ideia de deixar partir e atravessar como necessária à produção de uma leitura. "A leitura não extravasa da estrutura; fica-lhe submissa, precisa dela, respeita-a; mas perverte-a", lembra Barthes (2012, p. 26).

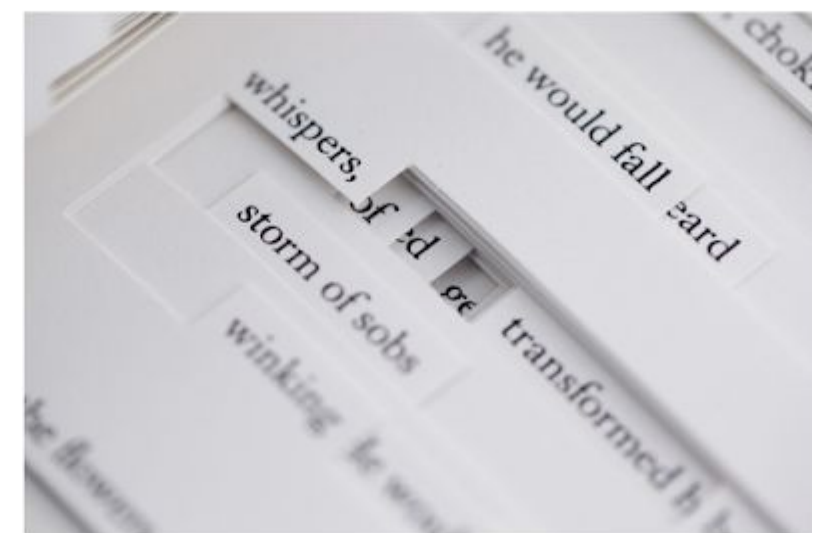

Figura 2 - Hole words

Fonte: Tree of codes.

\section{A ausência e a poética da extração}

Já na primeira página, o jogo presença-ausência, em Tree of codes, se faz de imediato, sem rodeios ou preliminares. Há um título e três parágrafos recortados. Não há palavras. $\mathrm{O}$ que "lemos" nesta primeira página? O buraco, o vazio, o apagamento, efeito de (re)cortes, extrações/subtrações que saltam aos olhos e ao (com)tato a cada vez que viramos uma página. Há algo ausente que pode se fazer presente, é isto que primeiramente nos salta aos olhos no encontro com a obra. A supremacia da ausência é nítida e palpável. O ausente, porém, está em estado vestigial, como um traço ou marca de uma presença. O que essa obra nos convida a pensar, já de início, é sobre o lugar da subtração na produção de um novo sentido - 
contrariando o senso comum que o pensa como derivado de um processo de adição. Para Wurth (2011, p. 4, tradução nossa), na união entre design e literatura, o que surge em Tree of codes assume um caráter escultórico: "Tree of codes hesita entre literatura e escultura. Posso colocá-lo em minha estante de livros ao mesmo tempo em que posso mostrá-lo como um objeto de exibição: todos os dias uma página diferente. ${ }^{7} \mathrm{~A}$ autora lembra a crítica feita por Faber, no The Guardian, ao dizer que talvez esta obra acabasse por perder o interesse do público como um livro e virasse "apenas" um artefato. Ao que ela responde que não haveria problema algum, e lembra que ninguém duvidou da autenticidade de Mallarmé como poeta quando elevou a poesia a uma constelação espaço-visual ao escrever Un coup de dés, em 1914.

Para Wurth (2011, p.4) Tree of codes é um texto que "faz" e não apenas “é", assim como na poesia concreta ${ }^{8}$. O arranjo do texto contorna a própria narrativa, o texto deixa apenas o essencial, sublinha a desintegração de alguns personagens e o performa através das palavras que caem e desmancham-se nos espaços em branco perdendo para sempre sua moldura fechada e retangular. Retomemos Foer:

\begin{abstract}
Minha tia estava reclamando. Era o principal fardo de sua conversa, a voz de carne branca e fértil, flutuando como fora dos limites de sua pessoa, mantida apenas vagamente nos grilhões de forma individual e, apesar desses grilhões, pronta para se multiplicar, para dispersar aquilo que se ramifica e se divide em uma família. Era uma fertilidade quase autopropagadora, uma feminilidade sem rédeas, morbidamente expansiva. (SCHULZ, 1977, p. 34, tradução nossa) ${ }^{9}$
\end{abstract}

$\mathrm{Na}$ escultura de Foer extraiu-se ou subtraiu-se para: "her ( )boundaries ( ) held only loosely ready to scatter" (FOER, 2010, p.17).O texto performa seu enredo, a fragmentação da personagem tia aparece no texto fragmentado de Foer: "ela ( ) limites-limiares ( ) segurada vagamente ( ) dispersar-se prontamente”. Foer ilumina através de seu livro-impossível o que é próprio, por exemplo, à poesia concreta: a coisificação da linguagem.

Uma união entre "forma" e "conteúdo" - esta antiga questão é a que continuamos voltando aqui: palavras, sua posição específica na página, e seu arranjo recortado, performam, em resumo, não apenas o que dizem, mas aquilo que pretendiam no

\footnotetext{
${ }^{7}$ No original: "Tree of Codes is still as much a work of literature as it is a work of sculpture: it hesitates in-between both. I can put it on my bookshelf, though I might also show it as a display object, every day a different page."

${ }^{8}$ Para Wurth, é importante diferenciar, no caso da intermedialidade de um texto, o que ele faz ( $d o$ ) e o que ele é (is).

${ }^{9}$ No original: "My aunt was complaining. It was the principal burden of her conversation, the voice of white and fertile flesh, floating as it were outside the boundaries of her person, held only loosely in the fetters of individual form, and, despite those fetters, ready to multiply, to scatter, branch out, and divide into a family. It was an almost self propagating fertility, a femininity without rein, morbidly expansive."
} 
contexto anterior, o que poderiam ter sido, ou, precisamente, o que nunca seriam (WURTH, 2014, p. 50)

As palavras com lugar específico na página e seus recortes não apenas fazem o que dizem, mas nos dão notícias de um contexto anterior ao qual pertenciam e não pertencem mais. Há a produção de um jogo em cena, no qual cada movimento de uma palavra poderia alterar toda a estrutura, assim como em uma escultura.

"[...]the whole of ( ) that year ( ) a ( ) day, ( ) transcendental hour ( ) a ( ) moment ( ) forever" (FOER, 2010, p. 63).O que Foer subtrai de Schulz? Os fragmentos que tentam contemplar uma quebra no tempo nos remetem à escrita de Schulz talvez como algo que permaneceu estagnada em um tempo, em eterno agora. "(o pai) não podia também fincar raízes em nenhuma realidade, e pairava eternamente na periferia da vida" (SCHULZ, 2012, p. 93).

Quando Foer, como vemos, faz uma "quebra" na continuidade do tempo - "o ano", "o dia", "uma hora transcendente", "um momento", "para sempre" -, ao lermos, precisamos tomar fôlego entre as palavras. O ritmo imposto à leitura acaba por literalmente quebrar uma espécie de continuidade ininterrupta que confere ao pai, em Schulz, uma espécie de existência paralisada num eterno agora. Ao longo da sequência das treze histórias de Schulz, o pai, Jakub, vai cada vez perdendo mais a razão.

Assim, por algumas semanas perdemos nosso pai de vista. Descia raramente, e, nessas ocasiões podíamos notar que tinha como que diminuído, ficado mais magro e encolhido. Às vezes se esquecia, levantando-se bruscamente da mesa e, adejando com as mãos feito asas, lançava um longo canto de galo, enquanto a bruma da neblina cerrava seus olhos. Depois, envergonhando-se, sorria conosco, esforçando-se para que todo esse incidente não passasse de uma brincadeira (SCHULZ, 2012, p. 37)

Em Schulz, Jakub (o nome do pai é uma das extrações de Foer), vai do estranho ao psicótico. É como se esta imagem do pai fosse, ao longo das histórias, borrando, como se o pai fosse esmaecendo, indo da sensatez à insensatez, da sanidade à loucura. Em Tree of codes o pai é uma figura que se caracteriza mais por um estado de ausência, como se vagasse feito

\footnotetext{
${ }^{10}$ No original: "A coincidence of "form" and "content" - this old issue is the issue we keep returning to here: words, their specific position on the page, the layout of that page, and its cut-out forms display, perform, in short, "do" not just what they say but what they may have purported in their previous context, what they might have been, or, precisely, never could have been".
} 
um zumbi. "Meu pai sozinho estava acordado, vagando silenciosamente pelos quartos." (FOER, 2010, p. 134, tradução nossa). ${ }^{11}$

Mas à noite quando minha mãe voltava da loja, meu pai animava-se, chamava-a e, com orgulho, mostrava-lhe os magníficos decalques coloridos, cuidadosamente colados nas páginas do livro principal. Foi então que todos percebemos que nosso pai começou a encolher, ficando cada dia menor, como uma noz que resseca dentro da casca. (SCHULZ, 2012, p. 29)

Esculpido por Foer para: "My father was ( ) wilting before our eyes. in undertones, pleading and begging ( ) he tried to reconcile with ( ) Mother ( ). Father called her and ( ) was almost overcome." (FOER, 2010, p. 87). ${ }^{12}$ O que em Schulz fala de um pai que encolhe feito uma noz dentro da casca, em Foer é um pai que tenta a reconciliação e aproximação com a mãe. Enquanto que no texto de Schulz o foco está na retirada de um pai para o mundo de sua própria imaginação, no qual briga consigo mesmo, sendo seu próprio juiz, no texto de Foer "ele tenta desesperadamente reconciliar-se com a mãe usando sua loucura para reparar seu relacionamento" (HAYLES, 2013, p. 229). Foer tenta reaproximar a mãe ao pai. No texto de Schulz raramente os dois estão interagindo, e quanto mais distante o pai se situa mais a mãe parece esquecê-lo. No texto de Schulz a mãe não é uma personagem central; Adela, a empregada, é uma mulher muito mais presente e com um papel muito mais significativo.

\footnotetext{
Minha mãe não tinha nenhuma influência sobre ele. Era Adela que chamava a sua atenção e a quem ele dava mostras de grande veneração. A arrumação da casa era para ele uma grande e importante cerimônia, que nunca deixava de presenciar, seguindo com uma mistura de medo e um frêmito de deleite todas as manipulações de Adela. (SCHULZ, 2012, p. 34)
}

Em uma pesquisa feita na Universidade de Duke, nos Estados Unidos (2013), um grupo se propôs a tarefa de digitalizar Tree of codes e A Rua dos Crocodilos. Com isso, chegou a alguns resultados quantitativos que são interessantes de observar. O estudo fez uma comparação palavra por palavra entre o texto de Schulz e o texto de Foer. O texto de Schulz, traduzido para o inglês, contém 37.483 palavras, e o de Foer, 3.815. A cada dez palavras de Schulz, em torno de nove foram eliminadas por Foer. As extrações não foram aleatórias, diz a pesquisadora:

\footnotetext{
${ }^{11}$ No original: "My father alone was awake, wandering silently through the rooms."

12 "Meu pai estava/ desaparecendo perante nossos olhos. com sentimentos atrapalhados implorava e mendigava/ ele tentava reconciliar-se com/ Mãe/. Pai/ a chamava/ estava quase superado.”
} 
Uma comparação feita na frequência das palavras nos dois textos revela alguns dos padrões que Foer usou para decidir quais palavras apagar. Todos os personagens minoritários ficaram de fora. Uma personagem importante, Adela, ficou de fora, a empregada que no texto de Schulz tem o poder através das atividades domésticas. Narrado na perspectiva de um garotinho (talvez de 10 anos) a maioria das histórias centram no comportamento errático do pai deste menino, que vai do estranho ao psicótico de acordo com a progressão das histórias. Adela é a única que consegue controlar este pai. (HAYLES, 2013, p. 128, tradução nossa) ${ }^{13}$

Segundo Hayles (2013), a mãe aparece com quatro vezes mais frequência em Tree of Codes que no texto original, sendo $0,42 \%$ do total de palavras contra $0,10 \%$ das palavras do texto anterior. Em Tree of codes, a mãe e o pai interagem diretamente, o que não percebemos nas histórias de Schulz. "Durante ( ) este inverno meu pai passava horas ( ) em esquinas ( ) como se ( ) procurando por ( ) Mãe ( ) e ( ) emergia ( ) coberto de pó.” (FOER, 2010, p. 32). ${ }^{14} \mathrm{O}$ pai procura pela mãe no texto de Foer como se procurasse uma espécie de reconciliação. A escultura de Foer transforma este trecho em "pleading and beginning ( ) he tried to reconcile with ( ) Mother (). Father called her and ( )was almost overcome" (FOER, 2010, p. 31). Na tradução ficaria como "implorando ( ) ele tentava reconciliar-se com ( ) Mãe ( )". Enquanto no texto de Schulz o foco é na "retirada" do pai para um mundo próprio, onde fica alheio ao mundo ao seu redor, em Foer ele está desesperado em aproximar-se da mãe e usa sua energia desviante, e talvez muito perto da loucura, para reparar a sua relação e o casamento.

À noite, quando minha mãe chegava da loja, ele estava excitado e propenso a brigas, acusava-a de imprecisão nas contas, enrubescia e assanhava-se até perder o controle. Lembro-me de certa vez, acordado no meio da noite, ver como corria de lá pra cá em cima do sofá de couro, só de camisa e descalço, demonstrando assim perante minha mãe toda perplexa a sua irritação. (SCHULZ, 2012, p. 26)

Se, ao folhear as páginas de Tree of codes, o que sentimos ao unir leitura e movimento em páginas recortadas e esburacadas é a delicadeza como necessária ao gesto do leitor, por outro lado, estas páginas delicadas são fruto de um trabalho brutal de corte, apagamento e extração da obra original. Porém, segundo Hayles (2013), a escultura de papel não é uma

\footnotetext{
${ }^{13}$ No original: "Comparison of word frequency in the two texts reveals patterns Foer used to decide which words to erase. Gone are all the minor characters, an especially important erasure in the case of Adela, a maid who in Schulz's text is the real power in the narrator household. Told from the perspective of a young boy (perhaps ten years old), most of the stories center on the increasingly erratic behavior of the boy's father, who goes from odd to psychotic as the stories progress and whom only Adela can control."

${ }^{14}$ No original: "During ( ) this winter my father would spend hours ( ) in corners ( ) as if ( ) searching for ( ) Mother ( ) and ( ) emerge ( ) covered with dust."
} 
simples ideia de representar, através da extração e do corte, toda a ausência e perda contida na vida e na obra de Schulz, que foi assassinado durante a Shoah. A narrativa proposta por Foer agrega uma complexidade que se desdobra não exclusivamente pelo novo enredo que se arma, mas especialmente pela forma que lhe dá lugar. Quanto à esta, gostaríamos de convidar o leitor a visitar o trabalho de Rosalind Krauss sobre a escultura, pois apostamos recolher dele alguns elementos que nos permitam atravessar parte da complexidade de Tree of codes para, dessa travessia, dar consistência ao que estamos denominando de poética da extração.

\section{O livro-escultura e o campo expandido}

Para Krauss, escultura não é uma categoria universal, mas uma categoria ligada à história. A autora aponta que, no modernismo, a produção escultórica começou a operar em relação a uma perda de lugar, produzindo o monumento como uma abstração, como um marco ou base, funcionalmente sem lugar e extremamente autorreferenciável. Podemos pensar a escultura como uma condição extremamente mutável de posição e significado. Atribuir a Tree of codes um lugar de livro-escultura é evidenciar o processo de retirada/extração, não apenas no que compõe a arquitetura do texto, mas em toda a narrativa, especialmente na construção e desconstrução das personagens. Retira-se algo de uma base, superfície, platus, e tem-se uma nova forma. Tomando a obra como uma escultura de papel, na qual o desenho arquitetônico de cada palavra molda determinada forma, uma digitalização da obra ou tradução aniquilariam a escultura. Como o lugar que cada palavra e cada buraco ocupam na página molda sua "escultura", uma tradução produziria uma escultura radicalmente diferente.

Para Krauss (1984, p. 129), a categoria escultura nos anos 60 passou a classificar tudo aquilo que não era arquitetura, o que estava sobre ou em frente a um prédio, e o que não era paisagem. Assim, a escultura se transformaria no conceito que resulta da soma da não-paisagem com a não-arquitetura e passa a assumir sua total condição de lógica inversa para se tornar pura negatividade, ou seja, a combinação de exclusões. Em sua concepção, a escultura deixou de ser algo positivo para se transformar na categoria resultante da soma da não paisagem com a não arquitetura (not-landscape not-architecture). É, assim, neste contexto que é articulado o campo expandido ou ampliado, pela problematização acerca de um conjunto de oposições, no qual a categoria modernista de escultura ficaria suspensa para 
pensar outras formas. Artistas do final da década de 60, como Robert Morris, Robert Irwin dentre outros, assumiram uma posição de ruptura histórica e cultural que não poderia mais ser descrita como modernista, e sim como pós-modernista.

O fato de ter a escultura se tornado uma espécie de ausência ontológica, a combinação de exclusões, a soma do nem-nenhum não significa que os termos que a construíram - não paisagem e não arquitetura - deixassem de possuir certo interesse. Isso ocorre em função de esses termos expressarem uma oposição rigorosa entre o construído e o não construído, o cultural e o natural, entre os quais a produção escultórica parece estar suspensa. (KRAUSS, 1984, p.129)

Explica a autora que, se esses termos são a expressão de uma oposição lógica de um par de negativos, então podem ser transformados através de uma simples inversão, nos mesmos polos antagônicos expressos de forma positiva. Em outras palavras, de acordo com a lógica de um certo tipo de expansão, a não arquitetura é simplesmente uma outra maneira de expressar o termo paisagem, e não paisagem é simplesmente arquitetura. Para a autora, é muito importante fazer um mapeamento desse momento, referindo-se ao pós-modernismo, ao nos propormos investigar a estrutura de qualquer intervenção no campo artístico contemporâneo.

Segundo Krauss, a abordagem de um campo expandido pressupõe a aceitação de rupturas definitivas e a possibilidade de olhar para o processo histórico de um ponto de vista da estrutura lógica. No pós-modernismo, a práxis não é definida em relação a um determinado meio de expressão - escultura -, mas em relação a operações lógicas dentro de um conjunto de termos culturais para o qual vários meios - fotografia, livros, linhas em parede, espelho ou escultura propriamente dita - possam ser usados.

Ao tomarmos Tree of codes dentro do binômio livro-escultura, também o incluímos neste espaço pós-modernista de expansão, em que vários meios diferentes de expressão podem ser utilizados para referir o livro ou o não livro.

Tree of codes é uma jornada extraordinária que ativa as camadas do tempo e espaço no manuseio de um livro e suas camadas de palavras. Jonathan Safran Foer habilmente desdobra uma maneira escultural de "artesanear" uma verdadeira história eloquente. No nosso mundo de telas ele é capaz de conectar conteúdo (ou narrativa) forma (ou materialidade) e a nossa experiência como leitores de um livro que nos faz lembrar a todo o momento que um livro tem um corpo. (ELIASSON, 2010, n. p., tradução nossa) ${ }^{15}$

\footnotetext{
${ }^{15}$ No original: "Tree of Codes [is] as extraordinary journey that activates the layers of time and space involved in the handling of a book and its heap of words. Jonathan Safran Foer deeply deploys sculptural means to craft a truly compelling story. In
} 
Pensar em um livro-escultura é também atribuir a este livro um duplo lugar de negação: uma forma que se define pela exclusão. Não é um livro, mas também não é uma escultura. É uma soma de exclusões. Não é um livro-objeto, não é uma obra de arte, não é uma escultura. Mas é um livro-escultura-objeto-obra-de-arte, porque não conseguimos atribuir que há ou não há o traço que lhe encaixaria em uma única classe.

$\mathrm{Na}$ escultura de palavras produzida por Foer há algo que retorna, mas através de um negativo. São as negações de sua condição, de não ser isto nem aquilo, que reaparecem na obra, nem livro, nem objeto, nem escultura, nem obra de arte, mas todos, e nenhum. No campo expandido da arte, para Krauss, os dois termos anteriormente vetados a ele, paisagem e arquitetura - termos esses que poderiam servir para definir o escultórico (como começaram a fazer no modernismo) somente na sua condição negativa ou neutra -, passam no pós-modernismo a serem seus constituintes.

O que vimos no transporte de Schulz para Foer é que algo permaneceu em estado de um resto. A extração radical de noventa por cento do texto de Schulz não foi feita sem consequências. Para Wurth (2011), as palavras dispersas nas páginas devastadas de Tree of codes exibem um aspecto crucial da memória de A Rua dos Crocodilos que pode, inclusive, lembrar o Em busca do tempo perdido, de Marcel Proust. N'A Rua dos Crocodilos, observamos não tanto uma busca de um tempo perdido, mas a busca de uma percepção de infância perdida, com uma grande linha que demarca o que é real, o que é imaginação, o que é lógico e o que é improvável. Wurth $(2011$, p. 5) lembra a frase cunhada por Collen Taylor há muito tempo atrás, quando disse: “É justamente isto que jaz no âmago de qualquer processo criativo: um senso de imaginação para sempre perdido" (TAYLOR apud WURTH, 2011, p. 8, tradução nossa).

\section{Considerações finais}

Conforme nos ensina Roland Barthes, ciência e literatura opõem-se no que concerne à maneira como ambas assumem a linguagem. Se na ciência a linguagem é instrumento que quer tornar transparente e neutro tanto quanto possível, na literatura a linguagem é o ser da

our world of screens. He welds narrative, materiality, and our reading experience into a book that remembers it actually has a body 
literatura - a linguagem poética "designa esse tipo de mensagem que toma sua própria forma por objeto, e não seus conteúdos" (BARTHES, 2012 p.5). Na poesia nenhum procedimento torna dispensável o recurso à leitura dos textos originais, isto é, há algo da forma que escapa à redução ao seu conteúdo. Na escultura de Foer, a extração/corte/subtração aparece já no título da obra: Street of Crocodiles extraída de sete letras origina Tree of codes. A obra insere-se em um movimento em que a arte vem quebrar uma série de paradigmas próprios à filosofia da representação. O pós-modernismo e seu caráter de inespecificidade arrebatam as fronteiras do que se entende como representado/representação.

Rosalind Krauss, na década de 1970, propôs a ideia de um expanded field para situar um novo tipo de obras artísticas que só podiam continuar a ser consideradas como esculturas se a própria categoria se expandisse até se tornar uma categoria infinitamente maleável. Para Garramuño (2014, p.33), “sua postulação é inspiradora para pensar uma literatura contemporânea que enfatiza o transbordamento de alguns dos limites mais conspícuos que haviam definido o literário com relativa comodidade, pelo menos até os anos 60". Não que estes parâmetros venham a definir ou construir uma periodização, mas dão indícios "de um campo expansivo, com conotações de implosões internas e de constante reformulação e ampliação - talvez seja mais apropriada para refletir sobre uma mutação daquilo que define o literário na literatura contemporânea" (GARRAMUÑO, 2014, p. 34). O que seria a literatura num campo expansivo? A autora nos faz lembrar de importantes textos brasileiros e argentinos que se aproximariam desse campo, como os últimos romances de João Gilberto Noll (desde Berkeley em Bellagio), de Marcos Siscar ( $O$ roubo do silêncio), de Martín Gambarotta (Punctum), Bernardo Carvalho (Nove noites: romance), entre tantos outros, sem esquecer ainda todo o campo da poesia. "Literature in the expanded field" é também o título de um artigo escrito por Marjorie Perloff, em 1993, em resposta ao Bernheimer Report, sobre a literatura comparada. Nesse artigo, segundo aponta Garramuño (2014), Perloff ataca ferozmente os participantes dessa conferência por expandirem os limites da literatura comparada para estudar os textos literários como uma prática discursiva entre outras e por proporem, diante dessa ideia de literatura num campo expandido, voltar à disciplina para estudar o "literário mesmo" dos textos. O que seria estudar o "literário mesmo" dos textos? Como abarcar neste campo do "literário mesmo" toda a articulação que tem sido feita com e-mails, blogs, fotografias, jornalismo etc.? E ainda, como situar, como na literatura aqui trabalhada, uma forma diferente de representação? Para Villa-Forte (2019, p. 53) em Escrever 
sem escrever: literatura e apropriação no século XXI, há entre o pensamento de Barthes e as práticas de apropriação contemporâneas (entre as quais insere-se Tree of codes), um diálogo que se estabelece por uma continuidade via uma diferença.

Retomemos aqui nosso olhar ao estudo feito na Universidade de Duke, nos Estados Unidos, sobre Tree of codes. A pesquisa digitalizou ambos os textos (de Schulz e de Foer), comparando página por página para poder quantificar as extrações em porcentagens! Hayles (2013) aponta Tree of codes como um texto deformado (deformational form). Atribuiu a isto o fato de ter encontrado ao longo de sua pesquisa um problema sem solução. As palavras-buraco (hole words) são o início do "problema". Além da fragilidade das páginas de difícil manipulação para fins de análise métrica, ao escanear as páginas era preciso escolher capturar ou não as palavras-buraco, e, em alguns casos, elas compõem o sentido narrativo da página que se está lendo. ${ }^{16}$ Mesmo com a digitalização do texto, a pesquisadora não conseguiu avançar na sua pesquisa. "Embora este método tenha nos possibilitado um texto escaneado que poderia ser analisado, o texto continuou nos colocando obstáculos que impediam uma análise completa" (HAYLES, 2013, p. 230) ${ }^{17}$.A pesquisadora demonstra dificuldades na análise pelos "obstáculos" do texto. Não foi possível determinar se as extrações foram feitas considerando ou não as palavras-buraco. Mesmo que à primeira vista a resposta fosse não, não é possível afirmar ou ter certeza. Ao tentar capturar a forma do texto, Hayles defronta-se com a impossibilidade de sua captura. Ao final do texto ficamos em dúvida se a autora considera o fator de uma literatura fora de si ou apenas sugere ser esta uma obra de impossível análise. É como se Hayles buscasse encontrar o "literário mesmo" da obra, mas sem sucesso. Concluímos, com isso, que Tree of codes carrega um caráter de inapreensão.

Ao escolher manter uma palavra de Schulz, ele poderia fazê-lo de duas formas que não seriam separadas por outra palavra mantida na página e o texto na página se manteria com qualquer uma das escolhas. Nestes casos ele poderia ter escolhido entre as duas opções através da localização dos buracos na página. (HAYLES, 2013, p. 230 , tradução nossa) ${ }^{18}$

\footnotetext{
${ }^{16}$ Ao final, a pesquisadora decidiu terminar sua codificação à mão, em detrimento do escaneamento.

${ }^{17}$ No original: "Although this method gave us a digitized text that could be analyzed, the text continued to trow us obstacles to a full analyses."

${ }^{18}$ No original: "When keeping a word in Schulz, Foer sometimes had the choice of two occurrences not separated by other kept wording. The retained text on the page would be the same with either choice. In these cases, he may have used the hole placement to decide between the two options."
} 
Por esse fator, a autora diz ter sido impossível examinar a obra de maneira quantitativa. Segundo a autora, esta impossibilidade é decorrente do fato de Foer ter "pré-deformado" seu texto, o que o faria resistir a outra deformação, mesmo esta "deformação" tendo sido fiel à sua fonte. O documento como forma de texto apresenta uma troca de fluxo de informações de um texto a outro livre de impedimentos. "Em Tree of codes, paradoxalmente, há uma força que empurra para a inércia da forma, mesmo sendo ele um material já deformado com respeito a sua fonte" (HAYLES, 2013, p. 230, tradução nossa). ${ }^{19}$

O livro-escultura-objeto-obra-de-arte impõe-se como fruto de um corte/extração que faz surgir este inquantificável. Existe algo deste ato do corte/extração que resiste à análise quantitativa de Hayles. Como objeto de análise, ele escapa. No artigo de Wurth (2011), “Old and new medialities in Foer's Tree of codes", podemos dizer que encontramos um outro ponto de vista acerca da impossibilidade de Tree of codes analisada no artigo de Hayles. Aqui, a "resposta" de Tree of codes ao seu problema central está na sua própria abertura. É como se aqui se considerasse o furo como parte do que a obra propõe. A possibilidade da rasura, do apagamento e da ausência não depõe contra a sua capacidade de transmissão, muito pelo contrário, é como se a ausência nos permitisse enxergar mais nitidamente um passado que existe por trás de cada presença.

Tree of codes reponde ao problema central n'A Rua dos Crocodilos oferecendo uma "abertura". Se as palavras falham, Tree of codes mostra uma possibilidade diferente: a possibilidade de deixar um branco, de apagar palavras para que então todo sentido inequívoco evapore com ele. Como leitores dos dois textos, vemos como esses buracos tornam a ausência presente, a ausência de palavras em uma página, a ausência de um passado que permanece no presente. (WURTH, 2011, p.2, tradução nossa) ${ }^{20}$

Para Wurth, Tree of codes responde ao problema central d'A Rua dos Crocodilos "offering openness", ou seja, oferecendo uma abertura. Na poética de Tree of codes vislumbramos uma abertura (openness) ao vazio, ao apagamento, à ausência. É como se Foer recolhesse as palavras deixadas de Schulz a cada vez que corta suas palavras. O que a poética

\footnotetext{
${ }^{19}$ No original: "in Tree of Codes, paradoxically been invested with inertial drag because the text is already materially deformed with respect to its source."

${ }^{20}$ No original: "Tree of Codes responds to this central problem in Street of Crocodiles by offering openness. If words fail, Tree of Codes shows a different possibility: the possibility to leave a blank, to erase words so that every unequivocal sense depriving reality of its suppleness and mutability - evaporates with it. As double readers (reading Tree of Codes with Street of Crocodiles) we see how these blanks make an absence present, the absence of words on a page, the absence of a past holding through the present."
} 
da extração em Schulz-Foer nos ajudou a vislumbrar é um trabalho poético de localização do impossível. Localização, sem captura.

\section{REFERÊNCIAS}

BACKES, Camila; MOSCHEN, Simone. Cortar para ler: o que Tree of codes pode nos ensinar sobre a arte da escuta. Psicologia Clínica, 2020. No prelo.

BARTHES, Roland. O rumor da língua. São Paulo: Editora Martins Fontes, 2012.

ELIASSON, OLAFUR. [Sem título]. In: FOER, Jonathan Safran. Tree of codes. Nova Iorque: Visual Editions, 2010. Não paginado.

FOER, Jonathan Safran. Tree of codes. Nova Iorque: Visual Editions, 2010.

GARRAMUÑO, Florência. Frutos estranhos: sobre a inespecificidade na estética contemporânea. Rio de Janeiro: Rocco, 2014.

HAYLES, Katherine. Combining close and distant reading: Jonathan Safran Foer's Tree of Codes and the aesthetic of bookishness. Modern Association of America (PMLA), v. 1, n. 128, p. 226-231, 2013.

KRAUSS, R. A escultura no campo ampliado. Rio de Janeiro: Gávea, 1984. Disponível em: http://monoskop.org/images/b/bc/Krauss_Rosalind_1979_2008_A_escultura_no_campo_amp liado.pdf. Acesso em: 20 abr. 2014.

KRAUSS, Rosalind. Sculpture in the expanded field. October 8, New York, 1979.

POLTIER, Naomi Pacific. Jonathan Safran Foer's use of poetry to create a purer novel.2016-2017. Disponível em:

https://www.studocu.com/en/document/university-of-oxford/creative-writing/essays/jonathansafran-foers-use-of-poetry-to-create-a-purer-novel/1694442/view. Acesso em: 18 set. 2019;

SCHULZ, Bruno. Ficção Completa. São Paulo: Cosac Naify, 2012.

. The Street of Crocodiles, New York: Penguin, 1977.

TREE of Codes by Jonathan Safran Foer. Visual Editions. Disponível em:

http://visual-editions.com/tree-of-codes. Acesso em: 13 out. 2017.

WURTH, Kiene Brillenburg. Old and new medialities in Foer's Tree of Codes. CLCWeb:

Comparative Literature and Culture, n. 13, p. 1-8, 2011.

Recebido em 30/09/2019. Aceito em 18/11/2019. 